\title{
AUDITORIA EM BANCOS: RELAÇÃO ENTRE OS ASSUNTOS CITADOS EM MODIFICAÇÃO DE OPINIÃO, ÊNFASE E PAA
}

\author{
AUDITING BANKS: RELATIONSHIP BETWEEN ISSUES CITED IN MODIFIED \\ OPINION, EMPHASIS AND KAM
}

\author{
LUCAS RODRIGUES SANTANA \\ Universidade de Brasília. Endereço: Campus Universitário Darcy Ribeiro, \\ Prédio da FACE/CCA | Asa Norte | 70.910-900 | Brasília/DF | Brasil. \\ D http://orcid.org/0000-0001-9947-2988 \\ lucassantana06@gmail.com
}

\section{FRANCIELLE JESUS SILVA}

Universidade de Brasília. Endereço: Campus Universitário Darcy Ribeiro, Prédio da FACE/CCA | Asa Norte | 70.910-900 | Brasília/DF | Brasil. (1) http://orcid.org/0000-0002-3146-3679

francielle1996@gmail.com

\author{
JOSÉ ALVES DANTAS \\ Universidade de Brasília. Endereço: Campus Universitário Darcy Ribeiro, \\ Prédio da FACE/CCA, Sala BT-54/4 | Asa Norte | 70.910-900 | Brasília/DF | \\ Brasil. \\ Dhttp://orcid.org/0000-0002-0577-7340 \\ josealvesdantas@unb.br
}

\section{DUCINELI REGIS BOTELHO}

Universidade de Brasília. Endereço: Campus Universitário Darcy Ribeiro, Prédio da FACE/CCA, Sala AT-08/4 | Asa Norte | 70.910-900 | Brasília/DF | Brasil.

(1) http://orcid.org/0000-0002-6205-2071

ducineli@unb.br

\section{RESUMO}

Este estudo teve por objetivo verificar a relação entre os assuntos citados como base para modificação de opinião, parágrafos de ênfase e principais assuntos de auditoria (PAA), nos trabalhos de auditoria realizados nos bancos brasileiros. Utilizando a técnica de análise de conteúdo, foram examinados os relatórios emitidos pelos auditores sobre as demonstrações de 134 Instituições Bancárias brasileiras, no período de 2007 a 2016, totalizando 746 relatórios. Os resultados dos exames revelaram que os assuntos relativos a créditos tributários, provisões passivas e questões atuariais são diretamente associados entre aqueles utilizados como base para opinião modificada, parágrafo de ênfase e PAA. A continuidade operacional é destaque tanto para modificação de opinião quanto ênfase, mas não como PAA. Como comportamento assimétrico destacam-se os assuntos mais citados para modificação de opinião (arrendamento mercantil) e como PAA (provisão para perdas em operações de crédito), que têm pouca relevância nos demais 
tópicos. A pesquisa contribui para o desenvolvimento da literatura nacional sobre auditoria, na medida em que avalia a associação entre os assuntos que têm merecido maior atenção dos auditores independentes na preparação dos seus relatórios sobre as demonstrações dos bancos brasileiros, seja como modificação de opinião, ênfase ou PAA - abordagem ainda não explorada na literatura sobre o tema.

Palavras-chave: Auditoria. Relatório de Auditoria. Opinião Modificada. Ênfase. PAA.

\begin{abstract}
The purpose of this study was to verify the relationship between the topics cited as a basis for modified opinion, emphasis paragraphs and the key audit matters (KAM) in the audit work carried out in Brazilian banks. Using the content analysis technique, the reports issued by the auditors on the statements of 134 Brazilian banking institutions, from 2007 to 2016, were examined, totaling 746 reports. The results of the examinations revealed that the topics related to deferred tax assets, provisions and actuarial passive issues are directly associated among those used as basis for modified opinion, emphasis paragraph and KAM. Operational continuity is prominent for both modified opinion and emphasis, but not as KAM. Asymmetric behavior is highlighted in the most cited issues for modified opinion (leasing) and KAM (provision for losses on credit operations), which have little relevance in the other topics. The research contributes to the development of the national literature on auditing, insofar as it assesses the association between the issues that have received more attention of the independent auditors in the preparation of their reports on the Brazilian banks' statements, whether as a modification of opinion, emphasis or KAM - an approach not yet explored in the literature on the subject.
\end{abstract}

Keywords: Audit. Audit Report. Modified Opinion. Emphasis. KAM.

\title{
1 INTRODUÇÃO
}

As instituições bancárias desempenham papel fundamental na economia, pois atuam como intermediador de oferta e demanda de recursos. Para desempenhar essas funções de forma segura, os bancos trabalham com a confiança. Nesse contexto, a opinião dos auditores independentes fornece credibilidade às demonstrações financeiras, contribuindo assim para a confiabilidade do sistema bancário, conforme destaca o Basel Committee on Banking Supervision (BCBS, 2002). No entanto, os grandes escândalos corporativos ocorridos no início do século estavam diretamente ligados a manipulações e fraudes contábeis e não obtiveram opinião modicada dos auditores independentes, além de ter casos em que a firma de auditoria estava envolvida nas fraudes. Esses fatos colocaram em evidência as empresas de auditoria e o alcance da responsabilidade dos auditores (Dantas \& Medeiros, 2015).

A crise financeira de 2007-2008, desencadeada por uma sucessão de falências de instituições financeiras nos Estados Unidos da América (EUA) e em países na Europa, reforçou a preocupação de investidores e stakeholders, que passaram a demandar mais credibilidade no mercado com relação às informações financeiras divulgadas pelas empresas (Gold, Gronewold \& Pott, 2012). As divulgações nos relatórios das empresas envolvidas na crise mundial não eram compatíveis com suas realidades econômicas, e essa situação gerou certo ceticismo com relação aos relatórios corporativos, inclusive os de auditoria (PwC, 2016; Girotto, 2016).

A repercussão do efeito econômico da opinião de auditoria, com ressalva ou com parágrafos de ênfase, pode indicar, por exemplo, a possível descontinuidade das operações da sociedade, tornando claro para os interessados na informação a incerteza sobre seus investimentos e, consequentemente, pode afetar a alocação dos recursos financeiros dos investidores. Nesse contexto, prever ou explicar relatórios de auditoria com ressalva ou com parágrafo de ênfase pode 
vir a ter implicações para os usuários das informações (Sparthis, 2003 como citado em Damascena e Paulo, 2013).

Nesse contexto, as normas profissionais devem estar atualizadas, a fim de melhorar os processos de auditoria e atribuir mais confiabilidade às demonstrações financeiras. Os reguladores, visando aprimorar as ações dos auditores, implementaram inovações normativas como o Projeto Clarity, empreendido a partir de 2004 pelo International Auditingand Assurance Standards Board (IAASB), com o patrocínio da International Federation of Accountants (IFAC) e o objetivo de desenvolver e implementar um conjunto de normas profissionais que assegure o desenvolvimento de trabalhos de asseguração de alta qualidade e que defina objetivamente as responsabilidades dos auditores independentes. Como resultado, foram editadas 36 International Standards of Auditing (ISAs), com vigência a partir de 2010, que no Brasil foram recepcionadas sob a forma de Normas Brasileiras de Contabilidade - de Auditoria Independente (NBC-TA).

O padrão do relatório de auditoria conta com parágrafos de responsabilização - da administração e dos auditores independentes -, o que delimita mais claramente a atuação e as responsabilidades de cada agente envolvido no processo de divulgação financeira. Os parágrafos de ênfase e de outros assuntos são caracterizados como prerrogativas a serem utilizadas pelos auditores. Quanto aos tipos de opinião, os relatórios de auditoria podem ser apresentados como: (i) relatório sem modificação, quando o auditor concluir que as demonstrações financeiras são elaboradas, em todos os aspectos relevantes, de acordo com a estrutura de relatório financeiro aplicável; ou (ii) relatório com modificação, nos casos em que o auditor concluir que as demonstrações tomadas em conjunto apresentam distorções relevantes, ou não conseguir obter evidência de auditoria apropriada e suficiente para formar opinião conclusiva sobre a fidedignidade das informações. Não se confundindo a opinião com modificação, há de se tratar dos parágrafos de ênfase que são utilizados pelos auditores para chamar a atenção dos usuários para aspectos relevantes para a compreensão das demonstrações financeiras (Castro, Vasconcelos \& Dantas, 2017; Damascena \& Paulo, 2013).

Na última mudança nas normas de auditoria, ocorrida em 2016, o IAASB emitiu e alterou as ISAs, com o objetivo de promover mudanças no relatório de auditoria para as empresas listadas. A inclusão dos principais assuntos de auditoria (PAA) foi a principal mudança no relatório, pois torna o documento mais informativo, além de abordar o que foi considerado relevante no trabalho da auditoria. Desse modo, criou-se uma expectativa relevante sobre os temas que seriam abordados como PAA.

Considerando esse contexto, a questão investigativa é: há relação entre os temas utilizados para modificação de opinião, elaboração de parágrafos de ênfase e definição dos PAA nos relatórios de auditoria sobre demonstrações financeiras dos bancos brasileiros?

O pressuposto é que haja uma associação entre os assuntos utilizados nos três tópicos, tendo em vista que traduzem questões mais relevantes para a compreensão das demonstrações (ênfase), refletem itens de maior preocupação no desenvolvimento dos trabalhos de auditoria (PAA) e representam aspectos mais sujeitos a distorções materiais nas informações financeiras (opinião modificada).

Assim, tendo como objeto de exame os trabalhos de auditoria desenvolvidos na indústria bancária brasileira, o presente estudo tem por objetivo avaliar a relação entre os temas: (i) apontados como justificativas para a modificação de opinião dos auditores; (ii) tratados nos parágrafos de ênfase; e (iii) definidos como PAA. Para o alcance desse propósito, utilizando-se da técnica de análise de conteúdo, são examinados 746 relatórios emitidos pelos auditores independentes sobre as demonstrações financeiras dos bancos brasileiros, num horizonte temporal de 10 anos, do período compreendido entre 2007 e 2016, com foco na análise das razões destacadas pelos auditores para justificar a modificação de opinião, para elaborar parágrafos de ênfase e para comunicar os PAA, buscando identificar se há relação entre eles.

A pesquisa contribui para o desenvolvimento da literatura nacional sobre auditoria, na medida em que avalia a associação entre os assuntos que têm merecido maior atenção dos auditores independentes na preparação dos seus relatórios sobre demonstrações dos bancos brasileiros, seja 
como modificação de opinião, ênfase ou PAA - abordagem que pode ser considerada como incipiente na literatura sobre o tema.

\section{REFERENCIAL TEÓRICO}

\subsection{O Papel da Auditoria}

Para o Public Company Accounting Oversight Board (PCAOB, 2002), a auditoria tem como objetivo aumentar o grau de confiança das demonstrações financeiras. Isso é alcançado por meio da emissão de opinião no relatório de auditoria pelo auditor independente, na qual o profissional avalia se as demonstrações estão em conformidade com a estrutura do relatório financeiro aplicável, isto é, os padrões contábeis estabelecidos pelos órgãos reguladores.

A International Federation of Accountants (IFAC, 2012) considera que a auditoria deve transmitir aos usuários das demonstrações financeiras a asseguração razoável obtida pelo auditor, e que os demonstrativos estão livres de distorções relevantes, seja por erro ou até fraude, mesmo não sendo objetivo do auditor encontrá-las. Nesse contexto, a auditoria independente é reconhecida como importante ferramenta de monitoramento para regular os conflitos de interesse e reduzir os custos de agência (Jensen \& Meckling, 1976; Pereira, Machado \& Pinheiro, 2017).

Murcia, Borba e Schiehll (2008) destacam que o auditor necessita fundamentar sua opinião através de evidências passíveis de verificação. Com base nessas evidências, o auditor independente deverá expressar uma opinião sobre a veracidade das informações contidas nas demonstrações contábeis em conformidade com os princípios contábeis geralmente aceitos.

As discussões a respeito das responsabilidades dos auditores estão em evidência mesmo após os novos modelos de governança propostos após a crise desencadeada pelo caso Enron, ou seja, o mercado de auditoria continua tendo que enfrentar questionamentos sobre sua efetividade e credibilidade (Dantas \& Medeiros, 2015). Alguns órgãos reguladores reagiram implementando algumas leis de regulação, como a Lei Sarbanes-Oxley, criada em 2002, nos Estados Unidos, com o objetivo de recuperar a credibilidade da informação contábil, aumentando o custo de litígio e o nível de governança corporativa (Mendonça, Costa, Galdi \& Funchal, 2010). Tendo em vista que as instituições financeiras dependem da credibilidade, o relatório dos auditores é uma peça importante nesse processo de confiabilidade do mercado perante essas entidades.

\subsection{Auditoria em Instituições Bancárias}

Os bancos são instituições financeiras privadas ou públicas que têm como objetivo principal proporcionar suprimentos de recursos necessários para financiar, a curto e a médio prazos, o comércio, a indústria, as empresas prestadoras de serviços e as pessoas físicas. A atividade dos bancos está relacionada com o risco, pois no processo de intermediação financeira promove a transformação de prazos, incorrendo em riscos de crédito, de mercado e de liquidez. Por esse motivo, a confiança e a credibilidade são de suma importância para as instituições financeiras (Dantas \& Medeiros, 2015), identificando-se uma relação objetiva com o trabalho desenvolvido pelos auditores independentes, que consiste em agregar confiança e credibilidade às informações divulgadas pelas entidades, por meio das demonstrações financeiras.

De acordo com Gallo e Nicolini (2002) e Pereira (2006), devido às novas pressões de mercado e aos escândalos financeiros verificados nos últimos anos, tornou-se necessário convencer os bancos, em nível global, a possuírem um sistema de informação na área de risco, de forma a geri-lo eficazmente. Por esse motivo, foi criado o BCBS, que tem como missão coordenar e formular diretrizes formalizadas por meio dos chamados Acordos de Basileia, que têm por objetivo criar exigências mínimas de capital para instituições financeiras, como forma de fazer face aos riscos aos quais o sistema financeiro está exposto. Esses dispositivos regulamentares, notadamente quanto à exigência de capital, não substituem nem reduzem a importância dos 
trabalhos de auditoria para a criação de um ambiente que seja caracterizado pela confiança, credibilidade e estabilidade. Manifestação nesse sentido é exposta pelo próprio BCBS (2002).

Para Kanagaretnam, Krishnan e Lobo (2010), não são comuns estudos de auditoria em instituições financeiras, devido a suas peculiaridades, seja em relação aos ativos ou operações e exigências dos órgãos reguladores. Os autores destacam que as evidências obtidas em outros segmentos não necessariamente se repetem no sistema bancário, exatamente pelo destacado fato de que os bancos operam em ambiente fortemente regulamentado, monitorados pelos bancos centrais e/ou outras agências reguladoras.

Conforme relatam Dantas e Medeiros (2015), devido à crise financeira de 2008, onde diversas empresas vieram a falência, as discussões sobre o hiato de expectativas em relação aos limites de responsabilidade dos auditores foram acentuadas, devido às investigações promovidas sobre o insucesso das firmas de auditoria em alertar dos riscos que levaram à crise bancária.

\subsection{Principais Assuntos de Auditoria (PAA)}

Com as alterações das ISAs, em 2016, os padrões do relatório do auditor independente passaram a incluir a ISA 701 - Communicating Key Audit Matters in the Independent Auditor's Report. No Brasil, essa norma foi recepcionada como NBC TA 701. Trata da responsabilidade do auditor em comunicar quais foram os PAA considerados em seu trabalho, ou seja, visa abordar o julgamento exercido pelo auditor sobre o que comunicar em seu relatório e também a forma e o conteúdo de tal comunicação. Essa norma se aplica para as auditorias realizadas em entidades listadas - com ações ou títulos de dívida negociados em bolsa.

A comunicação dos PAAs tem como objetivo tornar o relatório mais informativo, agregando maior transparência à auditoria realizada. A apresentação desses assuntos fornece informações adicionais aos usuários das demonstrações, contribuindo para que compreendam mais apropriadamente o que o auditor considerou como relevante na auditoria, além de auxiliar a entender a entidade e as áreas que envolveram julgamento significativo na preparação das demonstrações. São assuntos que, segundo o julgamento profissional do auditor, foram os mais significativos na auditoria das demonstrações do período corrente, sendo selecionados entre os comunicados aos responsáveis pela governança, ou seja, são aqueles que demandaram atenção significativa do auditor durante a condução dos trabalhos (PwC, 2016). O relatório de auditoria deve conter uma seção específica intitulada "Principais assuntos de auditoria" e o auditor deve descrever cada assunto, usando um subtítulo apropriado. A descrição deve conter o motivo pelo qual o assunto foi considerado como significativo e como foi tratado na auditoria.

Percebe-se, assim, que a atualização do relatório de auditoria começou com um desejo por mais informações por parte dos investidores. Mesmo que a alteração não tenha se traduzido em mudanças no escopo do trabalho de auditoria, representa um maior empenho por parte dos auditores na elaboração do relatório, além de transmitir maior transparência e confiança.

\subsection{Pesquisas Anteriores}

No Brasil, alguns estudos já abordaram o conteúdo dos relatórios de auditoria, tanto em relação à modificação de opinião, ao uso dos parágrafos de ênfase e aos PAA, conforme estudos apresentados nesse tópico. A inovação do presente estudo consiste em avaliar a associação entre si dos temas abordados nas três situações.

\section{a) Sobre Modificação de Opinião}

Entre os estudos realizados no Brasil sobre relatórios de auditoria com modificação de opinião podem ser destacados: Santos (2008), Silvestre, Sprenger e Kronbauer (2016), Spathis (2003), Peres e Peters (2017), Castro et al. (2017), Patrocínio, Coutinho, Reina e Reina (2017), entre outros.

Santos (2008), por exemplo, verificou que nas instituições financeiras a administração é mais propensa a trocar a firma de audioria quando recebe um parecer modificado por ressalvas e 
enfâses relevantes do que quando obtém um parecer limpo da firma de auditoria atual. A identificação dos principais motivos que ocasionaram a emissão de relatório de auditoria modificado das companhias listadas na B3, nos períodos pré e pós convergência das normas brasileiras aos padrões internacionais da contabilidade foi o objeto de estudo de Silvestre et al. (2016). Os exames das opiniões modificadas dos relatórios do período pré-convergência às normas, 2004 a 2007, mostraram que os motivos predominantes para opinião modificada eram principalmente investimentos e tributos. Já no período de 2010 a 2013, pós-convergência, os assuntos predominantes para opinião modificada foram investimentos e continuidade operacional.

Para Spathis (2003), a repercução do efeito econômico do parecer com modificação pode indicar a possível descontinuidade das operações da sociedade, tornando claro para os interessados na informação a incerteza sobre seus investimentos, e por conseguinte, pode afetar a alocação dos recursos financeiros dos investidores. Peres e Peters (2017) identificaram que de 613 empresas listadas no Brasil, 40 apresentaram relatórios dos auditores independentes sobre as demonstrações financeiras de 2015 com modificação, e 70\% dessas empresas, trocaram algum membro de sua administração.

A avaliação dos impactos da adoção das ISAs na opinião dos auditores sobre as demonstrações financeiras dos bancos brasileiros foi explorada por Castro et al. (2017). A avaliação foi feita em 478 relatórios entre os anos de 2006 a 2013 e constataram que houve um aumento da frequência de relatórios com modificação de opinião, mas que não foi estatisticamente relevante. Em relação aos assuntos mais abordados para justificar a opinião modificada, destacamse a reclassificação de operações de arrendamento mercantil, a apropriação indevida de receitas e despesas e questões de natureza atuarial.

Patrocínio et al. (2017) tiviram como propósito identificar os motivos de ressalvas ou de parágrafos de ênfase nos relatórios dos auditores, emitidos no período de 2010 a 2015, para as entidades listadas no segmento Novo Mercado da B3, constatando que houve um aumento na emissão de relatórios dos auditores com ressalvas ou abstenção de opinião devido à adoção das normas internacionais de contabilidade, refletindo que as entidades enfrentaram dificuldades para se adequar aos padrões internacionais.

\section{b) Sobre Parágrafos de Ênfase}

Em relação aos estudos sobre relatórios de auditoria com parágrafos de ênfase é possível destacar, a título de exemplos, Damascena e Paulo (2013), Castro et al. (2017) e Patrocínio et al. (2017).

Damascena e Paulo (2013) verificaram em sua pesquisa que variáveis contábeis e indicadores econômico-financeiros têm influência sobre a emissão de pareceres de auditoria com ressalva ou parágrafos de ênfase, nas empresas da B3, constatando que quanto maior o valor da empresa, menor a chance de ocorrer parágrafo de ênfase. O estudo de Castro et al. (2017), com foco na avaliação dos impactos da adoção das ISAs nos relatórios de auditoria sobre as demonstrações financeiras dos bancos brasileiros, também mapeou as principais causas para apresentação de parágrafos de ênfase, constatando que os créditos tributários constituíram o principal tema destacado pelos auditores.

Também há que se ressaltar o estudo de Patrocínio et al. (2017), que constatou que o critério adotado para a avaliação patrimonial dos investimentos foi o principal motivo para a emissão de parágrafos de ênfase nos relatórios de auditoria sobre as demonstrações das empresas listadas no segmento Novo Mercado da B3, de 2010 a 2015, evidenciando que as empresas não estariam adotando os critérios estabelecidos pelos padrões contábeis.

\section{c) Sobre os Principais Assuntos de Auditoria (PAA)}

Em relação ao uso dos PAA, Rocha (2016) destaca que o primeiro país a adotar o novo relatório de auditoria foi o Reino Unido, em 2013, antes mesmo de ter uma norma específica. Depois, a Holanda seguiu o mesmo caminho, e em 2014, junto com outros países, Áustria, Polônia, Suíça, Alemanha e Zimbabwe começaram a adotar o novo formato. 
No Reino Unido, foram realizados dois estudos pelo Financial Reporting Council (FRC) sobre a experiência do novo relatório de auditoria, sendo analisados os dois primeiros anos, sendo o primeiro estudo realizado com base nos relatórios de 2014 (FRC, 2015) e o segundo tendo por referência os relatórios de 2015 (FRC, 2016).

No primeiro ano, o FRC (2015) concluiu que na maioria dos casos os auditores fizeram alterações nos relatórios de auditoria que ultrapassaram as alterações necessárias pela FRC, isto é, os relatórios continham informações a mais do que havia sido solicitado. A conclusão particular da pesquisa foi que cada uma das empresas de auditoria adotou diferentes abordagens para o relatório. O FRC (2015) considerou o grau de inovação e a diversidade das abordagens adotadas muito encorajador, sendo encontradas mudanças nas seguintes áreas: divulgação da materialidade utilizada, comunicação ao Comitê de Auditoria sobre os assuntos considerados significativos, identificação dos riscos, explicação mais ampla e detalhada do processo de auditoria, e melhoria da apresentação dos relatórios de auditoria, utilizando Figuras. Além de tratar dos pontos positivos, o estudo do FRC apresentou pontos que precisavam ser melhorados, como explicações mais claras quanto aos riscos e materialidade e como eles influenciavam no trabalho de auditoria. Sendo assim, percebe-se que a experiência foi positiva, por permitir que os auditores fossem mais específicos nos relatórios, sendo que a descrição dos PAA tornou esses documentos mais informativos e transparentes para os usuários, principalmente os investidores.

As principais conclusões a respeito do estudo do segundo ano (FRC, 2016) foram: a melhoria na linguagem utilizada pelos auditores independentes, voltada para o usuário final, deixando de lado o uso de termos genéricos, principalmente, com descrições mais precisas quanto aos riscos, e a incorporação de maiores informações sobre a materialidade e descrição das áreas onde o julgamento profissional foi mais relevante. É importante destacar que o FRC percebeu que é preciso melhorar alguns pontos do novo relatório, como a avaliação do auditor quanto à qualidade dos controles internos da entidade e a visão do auditor sobre a adequação das estimativas de gestão, além de terem sentido falta de comunicação quanto às mudanças nas abordagens de auditoria, como no nível de materialidade que foi utilizado.

Outra pesquisa com esse foco foi realizada por Bédard, Besacier e Schatt (2014), que analisaram o efeito dos PAA's sobre os retornos anormais, o gerenciamento de resultados e os honorários de auditoria. Como os resultados não apresentaram resultados estatisticamente significativos, os autores concluíram que os PAA's têm efeito simbólico, porém reforçam que ambientes institucionais diferentes podem apresentar resultados diversos.

Christensen, Glover e Wolfe (2014) realizaram experimento com 141 investidores não profissionais, mas que eram formados em escolas de negócios. Os resultados mostraram que os PAA's afetam na decisão de investimento, pois os investidores expostos a relatórios de auditorias com PAA's tenderam a mudar suas decisão em maior proporção. Por outro lado, foi constatado que quando as soluções dos PAA's eram apresentadas, a decisão se mantinha, o que indica que a proposta de resolução dos problemas reportados aumenta a confiança do investidor. Marques e Souza (2017) procuraram identificar e analisar os PAA reportados nos relatórios dos auditores das empresas que compuseram o Ibovespa em 2016, onde os PAA reportados foram sobre Recuperabilidade dos ativos, Contingências, Reconhecimento de receitas e Projeção de resultados futuros para a realização de ativos.

No Brasil, o Instituto dos Auditores Independentes do Brasil (Ibracon, 2017) apresentou estudo que analisou a seção dos PAA de 546 companhias abertas, incluindo as 100 maiores empresas listadas na bolsa, não sendo considerados nesse estudo os fundos de investimentos. $\mathrm{Na}$ pesquisa foi constatado que em $32 \%$ dos relatórios analisados foi considerado como principal assunto de auditoria o valor recuperável de ativos não financeiros (impairment), por envolver premissas e julgamentos subjetivos. $\mathrm{O}$ reconhecimento de receita foi o segundo PAA mais encontrado nos relatórios, mostrando preocupação em relação às especificidades dos contratos.

Este trabalho tem como foco as instituições bancárias, enquanto no estudo feito pelo Ibracon foram consideradas empresas dos vários setores da B3. Esse foco mais restrito possibilita analisar detalhadamente os PAA encontrados nos relatórios dos bancos, e assim inferir as 
implicações do novo relatório de auditoria nesse mercado, que apresenta características muito particulares, incluindo os aspectos de regulação. Também há que se ressaltar que neste estudo não está se restringindo a entidades listadas, alcançando todos os tipo de arranjos e estruturas societárias.

\section{PROCEDIMENTOS METODOLÓGICOS}

Este estudo tem como objetivo verificar a relação entre os assuntos (i) apontados como justificativas para a modificação de opinião dos auditores, (ii) tratados nos parágrafos de ênfase e (iii) definidos como PAA nos relatórios dos auditores independentes sobre as demonstrações financeiras dos bancos brasileiros. Para o alcance desse propósito foram aplicados os procedimentos metodológicos descritos nas Etapas 1 a 5, com destaque para a utilização da análise de conteúdo (Bardin, 2010).

Foi realizada a Análise de Conteúdo nos relatórios de auditoria das demonstrações financeiras das empresas da amostra, identificando os itens de modificação de opinião, parágrafo de ênfase ou PAA, ou seja, quais temas foram abordados para justificar cada um desses posicionamentos por parte dos auditores independentes. A análise dos itens foi estruturada como segue: (i) pré-análise, descritos nas etapas 1 e 2; (ii) exploração preliminar dos itens a serem analisados, descrito na etapa 3; (iii) tratamento dos resultados, inferência e classificação, descritos nas etapas 4 e 5 .

Etapa 1: Seleção dos bancos objeto do estudo

A pesquisa tem como amostra as demonstrações financeiras dos 134 conglomerados ou instituições bancárias individuais não integrantes de conglomerados, com atuação no mercado brasileiro, na data-base dezembro/2016, conforme relatório IF. Data divulgada pelo Banco Central do Brasil (BCB), em seu sítio na internet.

\section{Etapa 2: Localização das demonstrações financeiras dos bancos selecionados da amostra}

A análise compreendeu as demonstrações financeiras referentes ao período de 2007 a 2016, por meio de consulta aos sítios dos bancos selecionados na Etapa 1. Também foram pesquisados os sítios da Comissão de Valores Mobiliários (CVM) e a Central de Balanços da Federação Brasileira de Bancos (Febraban). Foram encontrados e analisados 746 relatórios de auditoria sobre as demonstrações financeiras dessas instituições, distribuídas anualmente conforme Tabela 1. Como se percebe, quanto mais recente a data-base, maior o número de demonstrações localizadas.

Etapa 3: Identificação dos relatórios de auditoria com modificação de opinião, parágrafo de ênfase ou PAA

Os 746 relatórios de auditoria coletados na etapa anterior foram examinados, sendo constatado que 88 registraram modificação de opinião, 140 apresentaram parágrafo de ênfase e 31 , os PAA - que correspondem a $11,8 \%, 18,8 \%$ e $4,2 \%$ do total dos relatórios examinados, respectivamente. A Tabela 1 demonstra a composição temporal desses eventos, merecendo ressalva o fato de que os PAA só constam no último exercício da pesquisa (2016), vigência da NBC-TA 701.

Tabela 1

Número de relatórios de auditoria analisados em cada ano

\begin{tabular}{cccccccccccc}
\hline Exercícios & 2007 & 2008 & 2009 & 2010 & 2011 & 2012 & 2013 & 2014 & 2015 & 2016 & Total \\
\hline N..$^{\circ}$ Relatórios & 48 & 52 & 58 & 64 & 72 & 78 & 82 & 82 & 92 & 117 & 746 \\
\hline Opinião com modificação & 4 & 4 & 3 & 5 & 10 & 9 & 12 & 14 & 12 & 15 & 88 \\
Parágrafo de ênfase & 9 & 9 & 9 & 11 & 13 & 16 & 15 & 18 & 22 & 18 & 140 \\
PAA & 0 & 0 & 0 & 0 & 0 & 0 & 0 & 0 & 0 & 31 & 31 \\
\hline
\end{tabular}


Etapa 4: Mapeamento dos assuntos abordados para modificação de opinião, parágrafo de ênfase ou PAA

Com a utilização da técnica de análise de conteúdo, foram examinados os relatórios com modificação de opinião, parágrafo de ênfase e PAA destacados na etapa anterior, no sentido de identificar quais temas foram abordados para justificar cada um desses posicionamentos por parte dos auditores independentes. A partir desse mapeamento foram analisados os assuntos mais recorrentemente utilizados pelos auditores independentes para modificar opinião, apresentar como ênfase ou destacar como PAA, procurando identificar as razões que justificariam a eventual concentração em determinados temas.

Etapa 5: Análise da relação entre os temas utilizados para modificação de opinião, parágrafo de ênfase e PAA

De forma a identificar se há associação entre os temas mais utilizados em cada um dos tópicos abordados no presente estudo, foi promovida análise gráfica associando os assuntos: (i) utilizados como justificativa para modificação de opinião versus apresentados como ênfase; (ii) apresentados como ênfase versus destacados como PAA; e (iii) utilizados como justificativa para modificação de opinião versus destacados como PAA.

\section{ANÁLISE DE RESULTADOS}

Tendo por referência os procedimentos destacados na Seção 3, foram examinados os conteúdos dos 88 relatórios de auditoria com opinião modificada, dos 140 com parágrafos de ênfase e dos 31 com PAA, conforme Tabela 1. O propósito é, por meio da técnica de análise de conteúdo, categorizar os assuntos utilizados pelos auditores independentes para justificar cada uma das situações destacadas no relatório.

A partir da referenciada identificação dos temas mais abordados nos três tipos de relato detalhados nas Subseções 4.1 a 4.3 - os assuntos foram classificados por ordem alfabética, com código unificado: A1 - Ambiente de tecnologia; A2 - Arrendamento Mercantil; A3 - Capital e Operações Societárias; A4 - Continuidade operacional; A5 - Créditos tributários; A6 - Diferimento do resultado líquido negativo - Resolução 4036/11; A7 - Distorções nos Outros Resultados Abrangentes; A8 - Hedge accounting; A9 - Não reconhecimento de despesas; A10 - Normas e Regulamentos; A11 - Operações de créditos; A12 - Provisão estimada para créditos de liquidação duvidosa (PECLD); A13 - Provisões passivas; A14 - Questões atuariais; A15 - Reconhecimento indevido de ativos; A16 - Republicação de informações; A17 - Resultado de Part. Societárias; A18 - Valor justo de instrumentos financeiros; A19 - Valor recuperável de ativos; A99 - Outros assuntos.

\subsection{Assuntos Citados como Justificativas para Modificação de Opinião}

O exame dos 88 relatórios de auditoria com opinião modificada, no período de 2007 a 2016 revelou que para cada um deles foi destacado um único evento como justificativa, consolidando 88 eventos. Na Tabela 2 é sintetizado o mapeamento ou categorias dos assuntos mais abordados para modificação de opinião dos auditores.

Tabela 2

Assuntos mais citados como justificativas para modificação de opinião nos relatórios de auditoria sobre as demonstrações financeiras de bancos brasileiros - 2007 a 2016

\begin{tabular}{clccr}
\hline Cód & \multicolumn{1}{c}{ Assuntos Mencionados } & Quant. & \% Relat. & \% Eventos \\
\hline A2 & Arrendamento Mercantil & 17 & $19,3 \%$ & $19,3 \%$ \\
A5 & Créditos tributários & 12 & $13,6 \%$ & $13,6 \%$
\end{tabular}




\begin{tabular}{clcrr} 
A6 & Diferimento do resultado líquido negativo (Res. 4036/11) & 11 & $12,5 \%$ & $12,5 \%$ \\
A13 & Provisões passivas & 9 & $10,2 \%$ & $10,2 \%$ \\
A14 & Questões atuariais & 8 & $9,1 \%$ & $9,1 \%$ \\
A4 & Continuidade operacional & 6 & $6,8 \%$ & $6,8 \%$ \\
A7 & Distorções nos Outros Resultados Abrangentes & 5 & $5,7 \%$ & $5,7 \%$ \\
A9 & Não reconhecimento de despesas & 5 & $5,7 \%$ & $5,7 \%$ \\
& Outros & 15 & $17,0 \%$ & $17,0 \%$ \\
\hline & Total de Relatórios & $\mathbf{8 8}$ & & \\
\hline & Total de Eventos & $\mathbf{8 8}$ & & \\
\hline
\end{tabular}

Os dados revelam que os problemas relacionados às operações de arrendamento mercantil representam o principal assunto que justifica a modificação de opinião dos auditores sobre as demonstrações financeiras dos bancos brasileiros, no período de 2007 a 2016, representando $19,3 \%$ dos casos de opinião modificada no período. Isso se justifica, principalmente, devido à divergência entre o que as normas instituídas pelo regulador bancário brasileiro prevê como prática contábil e as diretrizes indicadas no modelo contábil adotado no mercado de capitais, que replica, por meio de pronunciamento do Comitê de Pronunciamentos Contábeis (CPC), as diretrizes das International Financial Reporting Standards (IFRS). Por essa razão, é comum os auditores destacarem que as demonstrações financeiras estão de acordo com as normas instituídas pelo regulador, mas que contrariam a estrutura conceitual da contabilidade.

Os créditos tributários também foram relatados várias vezes como justificativa para ressalvas, representando $13,6 \%$ dos relatórios e casos de modificação de opinião. Os argumentos para tal, geralmente residem na impossibilidade de se confirmar a perspectiva de realização desses ativos no prazo regulamentar de dez anos. No caso dos questionamentos quanto ao diferimento do resultado líquido negativo, que representam $12,5 \%$ dos eventos de modificação de opinião, isso está associado à faculdade estabelecida na Resolução $\mathrm{CMN} \mathrm{n}^{\circ} 4.036$, de 2011, de se diferir o resultado líquido negativo decorrente de renegociação de operação de crédito anteriormente cedida. Apesar dessa faculdade regulamentar, os auditores ressalvam as demonstrações em que esse valor é relevante, tendo em vista que contrariam os preceitos conceituais da contabilidade.

Questionamentos sobre as provisões passivas, a mensuração dos passivos atuariais e distorções nos outros resultados abrangentes são outros temas que também assumem relevância nos eventos de modificação de opinião dos auditores, o que se justifica pela subjetividade implícita no processo de reconhecimento e mensuração desses itens patrimoniais.

Por fim, ressalta-se os eventos relativos à continuidade operacional das entidades. Os seis eventos destacados envolveram os bancos Ficsa e Maxima. Para o Banco Ficsa se constatou a justificativa de reavaliação de estratégia, o qual decidiu suspender definitivamente suas operações de créditos e mudar o foco para a gestão da carteira atual com o objetivo de promover a desalavancagem da instituição. Já no Banco Máxima foi apontado o risco de insuficiência de margem para suportar os riscos de suas operações, que se caracteriza como um dos requisitos regulamentares mínimos necessários definidos por normas dos reguladores.

\subsection{Assuntos Apontados nos Parágrafos de Ênfase}

O segundo bloco de análise se concentra em identificar os assuntos mais recorrentemente apontados pelos auditores nos parágrafos de ênfase dos relatórios de auditoria sobre as demonstrações dos bancos brasileiros, de 2007 a 2016. Os resultados dessa análise estão categorizados na Tabela 3, ressaltando que a diferença entre os totais de relatórios e de eventos se justifica pelo fato de alguns relatórios apresentarem mais de um assunto nos parágrafos de ênfase. 
Tabela 3

Assuntos mais citados nos parágrafos de ênfase nos relatórios de auditoria sobre as demonstrações financeiras de bancos brasileiros - 2007 a 2016

\begin{tabular}{clccr}
\hline Cód & \multicolumn{1}{c}{ Assuntos Mencionados } & Quant. & \% Relat. & \% Eventos \\
\hline A5 & Créditos tributários & 36 & $25,7 \%$ & $23,8 \%$ \\
A13 & Provisões passivas & 21 & $15,0 \%$ & $13,9 \%$ \\
A3 & Capital e Operações Societárias & 18 & $12,9 \%$ & $11,9 \%$ \\
A10 & Normas e Regulamentos & 18 & $12,9 \%$ & $11,9 \%$ \\
A14 & Questões atuariais & 17 & $12,1 \%$ & $11,3 \%$ \\
A4 & Continuidade operacional & 16 & $11,4 \%$ & $10,6 \%$ \\
A16 & Republicação de informações & 10 & $7,1 \%$ & $6,6 \%$ \\
& Outros & 15 & $10,7 \%$ & $9,9 \%$ \\
\hline \multicolumn{2}{r}{ Total de Relatórios } & $\mathbf{1 4 0}$ & \\
\hline
\end{tabular}

Conforme sintetizado na Tabela 3, os assuntos relativos a créditos tributários são os mais abordados nos parágrafos de ênfase na amostra examinada, estando presente em $25,7 \%$ dos relatórios de auditoria com parágrafo de ênfase e em $23,8 \%$ de todos os eventos destacados. Esses casos são relacionados a ativos fiscais diferidos reconhecidos, mas a respeito dos quais os auditores destacam que foram calculados por meio de estimativas que dependem de futuros lucros tributáveis. As instituições financeiras com maior ocorrência dessa situação foram a Caixa Econômica Federal, Banco Pan, BRB, Banco Luso Brasileiro, Banco Semear e Banif.

Outros dois temas que integram a relação dos mais citados para justificar a modificação de opinião também merecem destaque entre os apontados nos relatórios de ênfase: as provisões passivas e as questões atuariais. De forma bem parecida com os créditos tributários, são itens patrimoniais a respeito dos quais há forte dose de subjetividade, o que justifica a preocupação dos auditores em enfatizar essa condição, sem necessariamente modificar a opinião a respeito das informações apresentadas pela administração.

Também de forma equivalente ao identificado nos casos de modificação de opinião, nos parágrafos de ênfase também merecem destaque os relatos sobre continuidade operacional com mudança apenas de abordagem. Nos parágrafos de ênfase, os relatos dos auditores se concentram principalmente em apontar mudanças operacionais promovidas pelas instituições no sentido de preservar a continuidade de suas operações.

As maiores novidades dos assuntos abordados nos parágrafos de ênfase, comparativamente àqueles utilizados para modificar opinião, são os relacionados a temas envolvendo o nível de capital regulatório e operações societárias - presentes em 12,9\% dos relatórios com ênfase - e atendimento a normas e regulamentos - também destacados em 12,9\% dos relatórios que apresentam parágrafo de ênfase. Os casos relativos ao nível de capital e a mudanças societárias são abordados, geralmente, quando ocorre incorporação de outros bancos, aumento de capital, transferências de controle acionário e investimentos. Já os temas relativos a normas e regulamentos são associados aos bancos que, de alguma forma, não respeitaram as normas regulamentares para determinadas operações.

Por fim, destaca-se o fato de que 10,7\% dos relatórios com parágrafo de ênfase reportam casos de republicação de informações. É uma situação tipicamente de ênfase, ou seja, quando a instituição financeira republicou informações e o auditor pretende enfatizar aos usuários das demonstrações, para os efeitos dessa republicação, que foi apresentada pela administração. 


\subsection{Assuntos Citados como Principais Assuntos de Auditoria (PAA)}

O terceiro bloco de análise se concentra na análise dos PAA destacados pelos auditores independentes nos relatórios sobre as demonstrações financeiras de 2016. Nesse caso, a limitação ao exercício de 2016 se justifica pelo fato de que esse foi o exercício em que entrou em vigência os termos da NBC-TA 701, que instituiu a previsão da incorporação dos PAA para as companhias abertas. Essa restrição às companhias abertas justifica o fato de que apenas 31 dos 117 relatórios de auditoria examinados em 2016 apresentam PAA.

A comunicação dos PAA tem como objetivo tornar o relatório mais informativo, agregando maior transparência ao documento. Como visto anteriormente, esses assuntos são aqueles que, segundo o julgamento profissional do auditor, foram os mais significativos na auditoria das demonstrações contábeis do período corrente. Sobre os assuntos que integram os PAA nos 31 relatórios, esses são sintetizados na Tabela 4, cabendo ressaltar que foram citados 107 assuntos, o que representa uma média de 3,5 PAA para cada relatório.

Tabela 4

Assuntos mais citados como PAA nos relatórios de auditoria sobre as demonstrações financeiras de bancos brasileiros - 2016

\begin{tabular}{|c|c|c|c|c|}
\hline Cód & Assuntos Mencionados & Quant. & \% Relat & \% Eventos \\
\hline A12 & $\begin{array}{l}\text { Provisão estimada para créditos de liquidação duvidosa } \\
\text { (PECLD) }\end{array}$ & 27 & $87,1 \%$ & $25,2 \%$ \\
\hline A5 & Créditos tributários & 16 & $51,6 \%$ & $15,0 \%$ \\
\hline A13 & Provisões passivas & 15 & $48,4 \%$ & $14,0 \%$ \\
\hline A1 & Ambiente de tecnologia & 14 & $45,2 \%$ & $13,1 \%$ \\
\hline A14 & Questões atuariais & 11 & $35,5 \%$ & $10,3 \%$ \\
\hline A18 & Valor justo de instrumentos financeiros & 9 & $29,0 \%$ & $8,4 \%$ \\
\hline A19 & Valor recuperável de ativos & 6 & $19,4 \%$ & $5,6 \%$ \\
\hline \multirow[t]{4}{*}{ A11 } & Operações de créditos & 5 & $16,1 \%$ & $4,7 \%$ \\
\hline & Outros & 4 & $12,9 \%$ & $3,7 \%$ \\
\hline & Total de Relatórios & 31 & & \\
\hline & Total de Eventos & 107 & & \\
\hline
\end{tabular}

O tipo de PAA mais encontrado nos relatórios se refere à provisão estimada para créditos de liquidação duvidosa (PECLD), que consta em 87\% dos relatórios com PAA e representam 25,2\% de todos os assuntos destacados. A análise dos argumentos utilizados pelos auditores independentes para considerar esse como um dos PAA revela, entre outras, as seguintes justificativas: a relevância do saldo das operações de crédito; as garantias recebidas para as operações de créditos concedidas; a situação econômica do país; e o julgamento da administração aplicado na estimação da provisão. Isso é coerente com a afirmação de Kanagaretnam, Krishnan e Lobo (2010) de que as provisões para perdas em operações de crédito representam os principais accruals das instituições bancárias, com alto grau de subjetividade, o que justifica a preocupação dos auditores, dos usuários e dos próprios reguladores sobre a prática contábil adotada pela administração nessa estimação.

Depois da PECLD, merecem destaque os relatos de PAA relativos aos temas créditos tributários, provisões passivas e questões atuariais, que já tinham surgido entre os assuntos mais recorrentemente utilizados pelos auditores para modificar opinião ou para apresentar ênfase. As justificativas dos auditores para considerar os créditos tributários como PAA, citam a relevância 
dos saldos desses ativos, a utilização de estimativas de rentabilidade futura e o impacto que eventuais alterações das premissas podem causar nas demonstrações financeiras. Para as provisões passivas, os argumentos estão relacionados à avaliação, que envolve estimativas complexas e relevantes. No caso das questões atuariais (benefícios a empregados), a justificação é que envolve premissas atuariais, onde os cálculos realizados incluem taxas de desconto, inflação e taxa de mortalidade, o que se reflete em complexidade no seu tratamento contábil.

A maior novidade em relação aos outros tópicos é a recorrência com que o ambiente de tecnologia é citado como PAA - presente em 45,2\% do total de relatórios. Como as atividades dos bancos, incluindo o registro de todas suas transações, que se refletem nas demonstrações financeiras, são dependentes do funcionamento adequado dos sistemas de tecnologia, é natural esse tipo de destaque atribuído pelos auditores independentes ao tema.

Outro tema que mereceu destaque como PAA foi o valor justo de instrumentos financeiros. Isso se justifica tanto pela relevância desses instrumentos na estrutura patrimonial dos bancos quanto pela subjetividade implícita no processo de mensuração desses instrumentos, quando eles não possuem negociação em um mercado secundário ativo.

\subsection{Relação entre os Assuntos de Modificação de Opinião, Ênfase ou PAA}

Concluído a categorização e o mapeamento dos assuntos mais citados nos três tópicos dos relatórios de auditoria - modificação de opinião, parágrafos de ênfase ou PAA - o passo seguinte consistiu em avaliar a associação entre eles, utilizando-se de análise gráfica. O pressuposto é que, apesar de utilizados com enfoque distinto, deve haver uma relação entre os temas que mais preocupam os auditores (PAA), que os auditores entendem como relevante enfatizar aos usuários (ênfase) e que distorcem materialmente as demonstrações financeiras (modificação de opinião).

A primeira relação estudada se concentra na associação entre os assuntos mais recorrentes de modificação de opinião e de ênfase, conforme Figura 1.

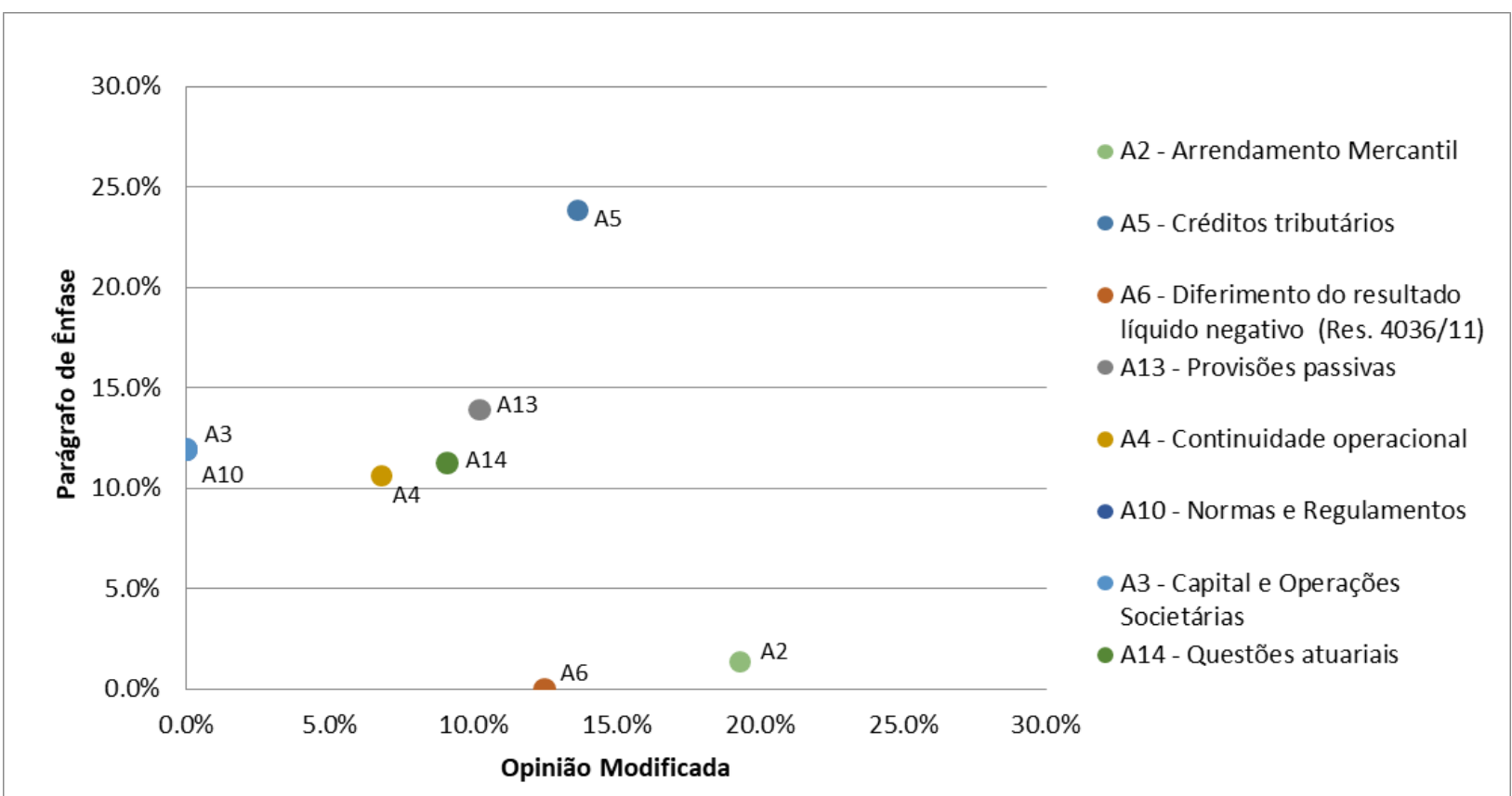

Figura 1. Relação entre os assuntos mais citados para modificação de opinião e parágrafos de ênfase nos relatórios de auditoria sobre as demonstrações financeiras de bancos brasileiros

A análise do Figura 1 revela, inicialmente, que os temas relativos a créditos tributários, provisões passivas, questões atuariais (benefícios a empregados) e continuidade operacional, nessa ordem de importância, são utilizados tanto como justificativa para modificação de opinião quanto como ênfase, revelando associação positiva entre as duas situações.

No caso dos assuntos relativos às operações de arrendamento mercantil e ao diferimento 
do resultado líquido negativo, admitido pela Resolução CMN no 4.036, de 2011, são utilizados basicamente para justificar opinião modificada. Por outro lado, os temas relativos a capital regulatório e operações societárias e a normas e regulamentos são tratados exclusivamente como elementos destacados em parágrafos de ênfase. Essa assimetria revela que os dois primeiros temas são eminentemente contábeis, não merecendo destaque como ênfase, embora configurem distorções materiais nas demonstrações, enquanto o segundo bloco traduz questões relevantes do ponto de vista do negócio das instituições bancárias, embora não traduzam distorções nas demonstrações financeiras.

A segunda relação analisada avalia a associação entre os assuntos utilizados como parágrafo de ênfase e os denominados PAA. Essa associação é demonstrada no Figura 2.

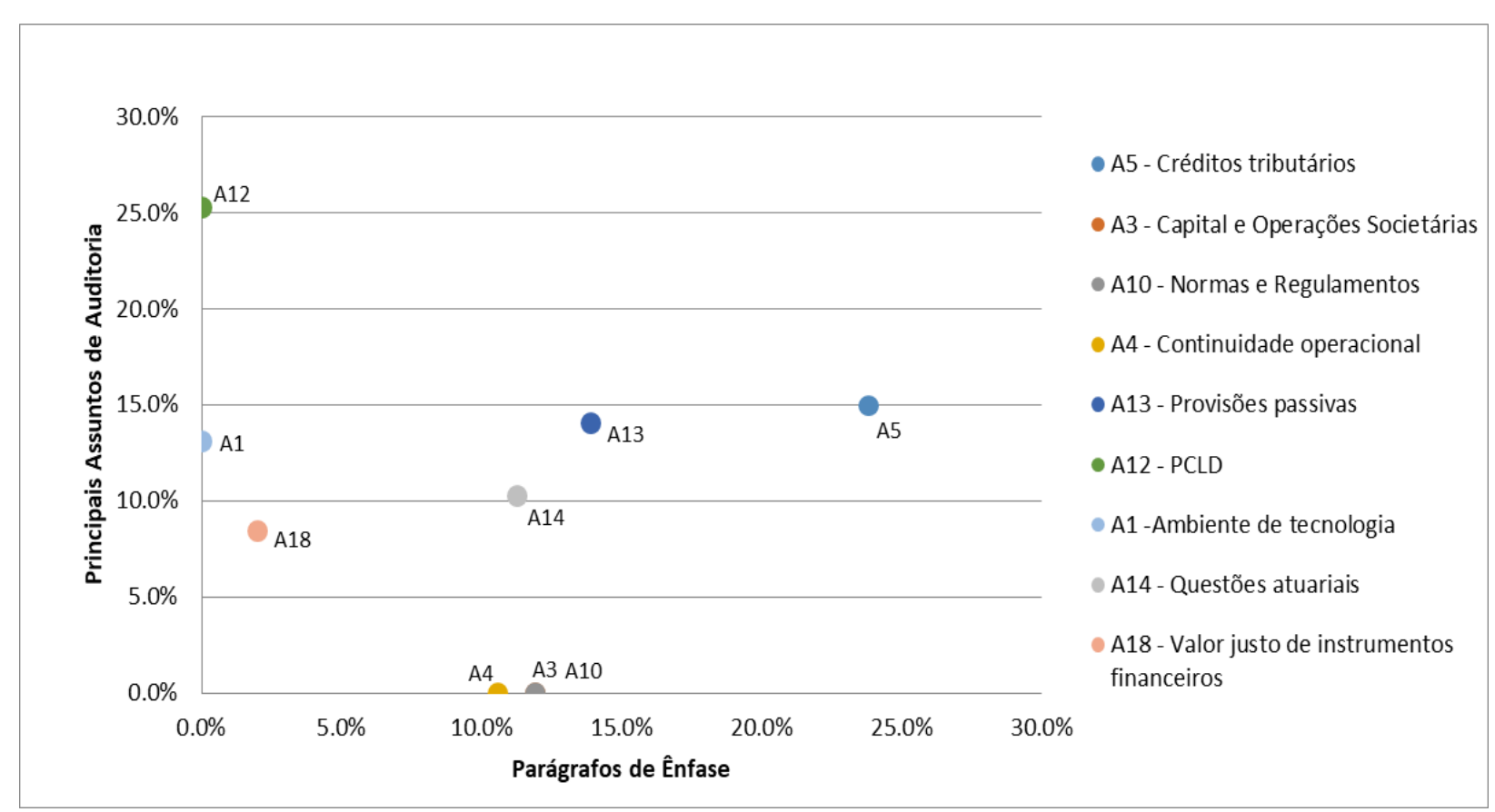

Figura 2. Relação entre os assuntos mais citados para parágrafos de ênfase e como PAA nos relatórios de auditoria sobre as demonstrações financeiras de bancos brasileiros

De forma equivalente ao constatado na associação entre os assuntos utilizados como modificação de opinião ou ênfase, a Figura 2 revela que os temas relativos a créditos tributários, provisões passivas e questões atuariais são comuns tanto nos parágrafos de ênfase quanto nos PAA, embora os créditos tributários sejam proporcionalmente mais recorrentes nas ênfases.

Em termos assimétricos, os temas relativos a PECLD, ambiente de tecnologia e valor justo de instrumentos financeiros são destacados como PAA e ignorados em termos de parágrafos de ênfase. Em contrapartida, entre os temas mais ressaltados como ênfase destacam-se os relacionados a capital e operações societárias, a normas e regulamentos e à continuidade operacional, que não foram citados entre os PAA. Desses, destaca-se o fato de a preocupação com a continuidade operacional não ter sido citada como PAA, dada a criticidade do tema. Talvez isso se justifique em função de os PAA serem exigidos apenas para as companhias listadas, o que restringe o seu alcance.

O terceiro bloco de análise se concentra na relação entre os assuntos que deram origem a modificações de opinião e os PAA, destacados nos relatórios de auditoria sobre as demonstrações financeiras dos bancos, conforme evidenciado na Figura 3. 


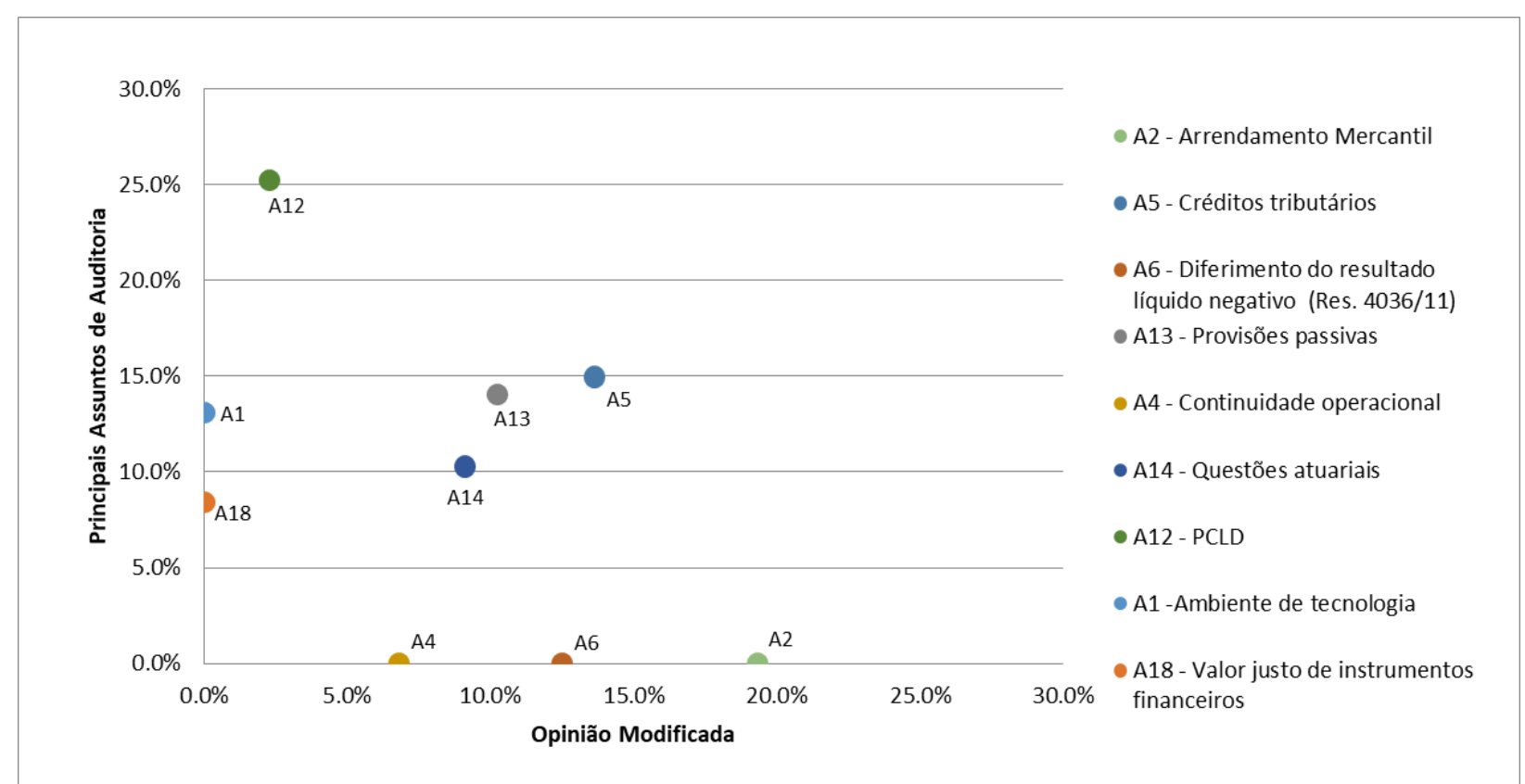

Figura 3. Relação entre os assuntos mais citados para modificação de opinião e como PAA, nos relatórios de auditoria sobre as demonstrações financeiras de bancos brasileiros

Outra vez, os assuntos relativos a crédito tributário, provisões passivas e questões atuariais (benefícios a empregados) são usados tanto para os auditores modificarem opinião quanto para destacarem como um PAA, identificando-se uma relação simétrica entre os tópicos.

Como assuntos utilizados eminentemente como PAA, destacam-se a PECLD - o tema mais recorrente como PAA, mas que praticamente não gerou distorções materiais nas demonstrações a discussão sobre o ambiente de tecnologia e o valor justo de instrumentos financeiros. No outro extremo, os temas muito utilizados para modificar opinião e que não apareceram como PAA foram os referentes a operações de arrendamento mercantil, diferimento do resultado líquido negativo e continuidade operacional. As potenciais razões para essas assimetrias parecem ser as mesmas explicitadas nas discussões das Figuras 1 e 2.

\section{CONCLUSÕES}

Este estudo teve por objetivo verificar a relação entre os assuntos citados nos parágrafos de ênfase, nas bases para opinião com modificação e nos PAA. Para esse fim, foram examinados os relatórios emitidos pelos auditores sobre as demonstrações dos 134 bancos brasileiros, de 2007 a 2016, totalizando 746 relatórios, utilizando-se a técnica de análise de conteúdo. Posteriormente, foi avaliada graficamente a relação entre os seis assuntos mais citados como base para modificação de opinião, as ênfases e os PAA.

Os resultados revelaram na primeira análise - Opinião com Modificação versus Ênfase que assuntos como arrendamento mercantil e diferimento do resultado líquido foram tratados apenas nas opiniões modificadas. Por outro lado, temas como capital regulatório e operações societárias e normas e regulamentos foram apontados apenas nos parágrafos de ênfase, revelando uma assimetria entre os temas eminentemente contábeis e as questões relativas aos negócios das instituições bancárias. Concluiu-se ainda, como associação positiva, a existência de assuntos como créditos tributários, provisões passivas, questões atuariais e continuidade operacional.

Na segunda análise - Ênfase versus PAA - é preservada a relação positiva da primeira análise, exceto quanto à continuidade operacional, a qual aparece apenas nas ênfases. Nos aspectos de assimetria, constatou-se temas como PECLD, ambiente de tecnologia e valor justo de instrumentos financeiros, observados apenas nos PAA. Citados apenas nos parágrafos de ênfase destacam-se os assuntos relacionados ao capital e operações societárias, a normas e regulamentos 
e à continuidade operacional.

A terceira análise - Opinião com Modificação versus PAA - evidencia a PECLD como tema mais recorrente como PAA, no entanto praticamente não gerou distorções materiais nas demonstrações analisadas. Assuntos como ambiente de tecnologia e valor justo de instrumentos financeiros não aparecem como base para modificação de opinião. Em contrapartida, os temas mais utilizados para modificar opinião e que não apareceram como PAA foram os referentes a operações de arrendamento mercantil, diferimento do resultado líquido negativo e continuidade operacional.

Como principal limitação, destaca-se a dificuldade em coletar as demonstrações de todas as instituições bancárias da amostra, principalmente as entidades de menor porte, podendo ocasionar algum tipo de viés na análise dos resultados, tendo em vista que os relatórios dos maiores bancos foram identificados para todo o horizonte temporal do estudo. Como sugestões para estudos futuros, recomenda-se o acompanhamento do uso dos PAA, tendo em vista o pouco tempo de vigência dessa inovação no processo de comunicação dos auditores. Além do mais, sugere-se a ampliação da análise da relação entre os assuntos utilizados para modificar opinião, elaborar ênfase e destacar PAA no âmbito das entidades não financeiras, tendo em vista que essas devem oferecer um nível de heterogeneidade mais amplo do que o segmento financeiro.

\section{REFERÊNCIAS}

Bardin, L. (2010). Análise de Conteúdo (4a ed.). Lisboa: Edições 70.

Basel Committee on Banking Supervision (BCBS). (2002). The relationship between banking supervisors and banks' external auditors. Disponível em Recuperado de http://www.bis.org/publ/bcbs87.pdf

Bédard, J., Gonthier-Besacier, N., \& Schatt, A. (2014). Costs and benefits of reporting Key Audit Matters in the audit report: The French experience. In International Symposium on Audit Research. Available at: http://documents. escdijon. eu/pdf/cig2014/ACTESDUCOLLOQUE/BEDARD_GONTHIER_BESACIER_SCHATT. pdf

Castro, R. L. C., Vasconcelos, J. P. B., \& Dantas, J. A. (2017). Impactos das Normas Internacionais de Auditoria nos Relatórios dos Auditores sobre as Demonstrações Financeiras dos Bancos Brasileiros. Revista Ambiente Contábil, 9(1), 1-20.

Christensen, B. E., Glover, S. M., \& Wolfe, C. J. (2014). Do critical audit matter paragraphs in the audit report change nonprofessional investors' decision to invest? Auditing: A Journal of Practice \& Theory, 33(4), 71-93.

Damascena, L. G., \& Paulo, E. (2013). Pareceres de Auditoria: Um Estudo das Ressalvas e Parágrafos de Ênfase Constantes nas Demonstrações Contábeis das Companhias Abertas Brasileiras. Revista Universo Contábil, 9(3), 104-127.

Dantas, J. A., \& de Medeiros, O. R. (2015). Determinantes de qualidade da auditoria independente em bancos. Revista Contabilidade \& Finanças, 26(67), 43-56.

Financial Reporting Council (FRC) - (2015). Extended Auditors' Reports - A review of experience in the first year. Recuperado em 10 junho, 2018, em https://www.cafr.ro/uploads/3.\%20Extended-auditors-reports-0773.pdf 
Financial Reporting Council (FRC) - (2016). Extended Auditors' Reports - A further review of experience. Recuperado em 10 junho, 2018, em https://www.frc.org.uk/getattachment/76641d68-c739-45ac-a251-cabbfd2397e0/Reporton-the-Second-Year-Experience-of-Extended-Auditors-Reports-Jan-2016.pdf

Gallo, G., \& Nicolini, D. (2002). Basilea II y la fragilidad bancaria en países emergentes. Caso Peruano 1997-2000. Lima: Universidad del Pacífico.

Girotto, M. (2016). Normas do Novo Relatório do Auditor Independente são publicadas pelo CFC. Recuperado de http://cfc.org.br/noticias/normas-do-novo-relatorio-do-auditorindependente-sao-publicadas-pelo-cfc/

Gold, A., Gronewold, U., \& Pott, C. (2012). The ISA 700 auditor's report and the audit expectation gap-Do explanations matter? International Journal of Auditing, 16(3), 286-307.

Instituto dos Auditores Independentes do Brasil (IBRACON). (2017). A experiência da aplicação do Novo Relatório do auditor. São Paulo: Ibracon.

International Auditing and Assurance Standards Board (IAASB). (2016). More Informative Auditors' Reports - What Audit Committees and Finance Executives Need to Know. Recuperado em 10 junho, 2018, em https://www.ifac.org/publications-resources/moreinformative-auditors-reports-what-audit-committees-and-finance

International Federation of Accountants (IFAC). (2012). Apoio da IFAC a um conjunto único de normas de Auditoria: Auditorias de Entidades de Pequeno e Médio Porte. Recuperado de http://www.ibracon.com.br/downloads/pdf/policyPositionPaper_2_Final.pdf

Jensen, M. C., \& Meckling, W. H. (1976). Theory of the firm: managerial behavior, agency costs and ownership structure. Journal of Financial Economics, 3(4), 305-360.

Kanagaretnam, K., Krishnan, G. V., \& Lobo, G. J. (2010). An empirical analysis of auditor independence in the banking industry. The Accounting Review, 85(6), 2011-2046.

Marques, V. A., \& Souza, M. K. P . (2017). Principais Assuntos de Auditoria e Opinião sobre o Risco de Descontinuidade: Uma Análise das Empresas do Ibovespa. RIC - Revista de Informação Contábil, 11(4), 1-22.

Mendonça, M. M., Costa, F. M., Galdi, F. C., \& Funchal, B. (2010). O impacto da Lei SarbanesOxley (SOX) na qualidade do lucro das empresas brasileiras que emitiram ADRs. Revista Contabilidade \& Finanças, 21(52).

Murcia, D. F., Borba, J. A., \& Schiehll, E. (2008). Relevância dos Red Flags na Avaliação do Risco de Fraudes nas Demonstrações Contábeis: a Percepção de Auditores Independentes Brasileiros. Revista Universo Contábil, 4(1), 25-45.

Patrocínio, E. A., Coutinho, R. S., Reina, D. R. M., \& Reina, D. (2017). Relatório de Opinião dos Auditores nas Empresas do Novo Mercado: Principais Motivos de Ressalvas e de Parágrafos de Ênfase. RAGC, 5(21).

Pereira, J. M. (2006). Gestão do risco operacional: uma avaliação do novo Acordo de Capitais Basiléia II. Revista Contemporânea de Contabilidade, 1(6), 103-124. 
Pereira, F. R., Machado, N. V., \& Pinheiro, L. E. (2017). Auditoria Contábil: Um estudo acerca da relação entre o relatório dos auditores e as características da empresa auditada. Anais do Congresso USP de Iniciação Científica em Contabilidade, São Paulo, Brasil, 14.

Peres, L. J., \& Peters, M. R. S. (2017). Relatório de Auditoria com modificação e a troca da administração em companhias listadas. Revista Científica Hermes, (18), 292-303.

PricewaterhouseCoopers (PwC) (2016). Demonstrações financeiras e sinopses normativa $e$ legislativa 2016/2017 (26a ed.). São Paulo: PricewaterhouseCoopers.

Public Company Oversight Board (PCAOB). (2002). AS 1001: Responsibilities and Functions of the Independent Auditor. Recuperado de https://pcaobus.org/Standards/Auditing/Pages/AS1001.aspx

Rocha, D. (2016). Contagem regressiva para o novo relatório de auditoria. Revista RI - Relação com Investidores, 207.

Santos, F. P. (2008). A relação entre o parecer de auditoria e a troca de auditores: uma investigação nas instituições financeiras. Dissertação de mestrado, Fundação Getúlio Vargas, Rio de Janeiro, RJ, Brasil.

Silvestre, A. O., Sprenger, K., \& Kronbauer, C. A. (2016). Relatório Modificado de Auditoria : Análise Pré e Pós-Convergência aos Padrões Internacionais. Revista Catarinense da Ciência Contábil, 15(44), 75-85.

Spathis, C. T. (2003). Audit qualification, firm litigation, and financial information: an empirical analysis in Greece. International Journal of Auditing, 7(1), 71-85. 